\title{
OPTIMIZED FEASIBILITY ANALYSIS FOR THE DESIGN TO SET UP SOLAR POWER PLANT DURING OPERATING HOURS IN THE ACADEMIC E-BLOCK AREA - CASE STUDY
}

\author{
Gagandeep Kaur ${ }^{1}$, Bhanu Duggal ${ }^{2}$ and Bhanu Marwaha ${ }^{3}$ \\ ${ }^{1}$ Assistant Professor, Electrical and Instrumentation Department, Thapar University, Patiala ${ }^{2}$ Student, Electrical and Instrumentation \\ Department, Thapar University, Patiala ${ }^{3}$ Student, Electrical and Instrumentation Department, Thapar University, Patiala
}

\begin{abstract}
This paper is regarding the optimized design feasibility analysis of a solar power plant in our academic area i.e. E-block in Thapar University. For this design analysis, the technical feasibility and financial feasibility has been considered completely. Further, the technical feasibility of the project puts emphasis on irradiation analysis, connected load analysis, rooftop analysis, shadow analysis, load analysis, design of the on-grid system as well as design of the off-grid system. Financial feasibility analysis includes Cost analysis, Payback period, Funding options. This paper also discusses the type of solar power system to be installed based on the conclusions drawn out of the technical analysis for optimal solution for the utilization of block based analysis specifically. The financial feasibility also supports the selection.
\end{abstract}

\section{Introduction}

India is currently ranked sixth in annual electricity consumption, accounting for about $3.5 \%$ of the world's total energy consumption. India's electricity consumption has risen by about $64 \%$. The electricity consumption is expected to rise at rate of $8 \%$ annually through 2020 . There lies an ironic fact that although the consumption of electricity may be very high but the per capita consumption is as low as $1010 \mathrm{kWh}$ in 2014-15 as opposed to $15000 \mathrm{kWh}$ per capita in developed nations. Another, interesting fact is that nearly one fourth of Indian households still have no access to electricity with some states in East and North East having less than even $30 \%$ households with access. In this developing countries, like India, currently there are about 400 million people i.e. about 80 million households do not have access to commercial energy and still are not connected from the grid.

Hence, renewable energy comes to the rescue for the growing energy needs of India and the energy crisis which is prevalent in India. It will solve the problem of grid disconnectivity. India has been endowed with abundant natural resources that there will be more than enough to mitigate the energy crisis. Even, then we see that renewable energy is still not utilized as per the need of the hour. The following bar graph analysis shows the same in the figure 1. This is the output data of year 20132014. Now, government is putting emphasis to utilize this energy and putting forward so many plans to promote it commercially as well as promote its $\mathrm{R} \& \mathrm{D}$.

\footnotetext{
${ }^{\mathrm{a}}$ Corresponding author: pps11may76@gmail.com
}

Government with the schemes like Jawaharlal Nehru solar mission and subsidies encourages it. According to Jawaharlal Nehru National Solar Mission (JNNSM), India aims for setting up $100 \mathrm{GW}$ capacity in solar energy which includes $40 \mathrm{GW}$ as rooftop type and $60 \mathrm{GW}$ as ground mounted type.

\section{ALL INDIA POWER INSTALLED CAPACITY}

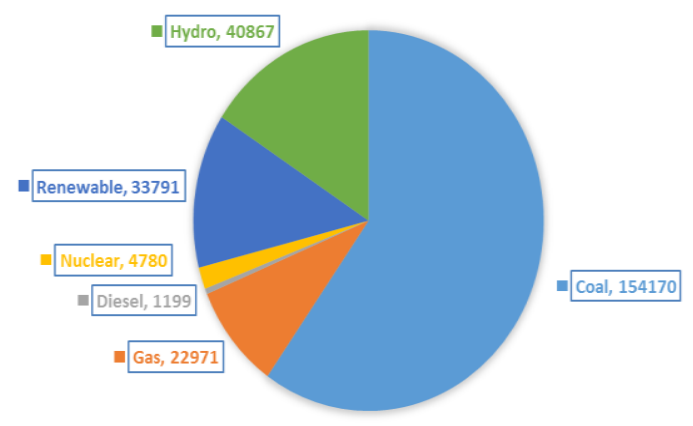

Figure 1.All India Power Installed Capacity [1] 
Renewable Power Installed Capacity

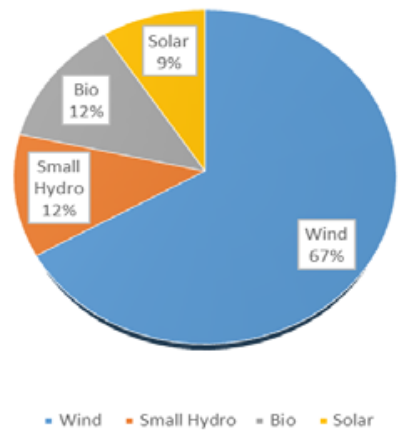

Figure 2. Renewable Energy Analysis [2]

Thus, the renewable energy has attracted many investors, primarily due to government policies and the return benefits. The renewable revolution has been set in motion but it still needs time to catch up with existing conventional electricity generation plants. The renewable energy analysis is shown in the figure 2.

RENEWABLE ENERGY INSTALLED CAPACITY GROWTH MW

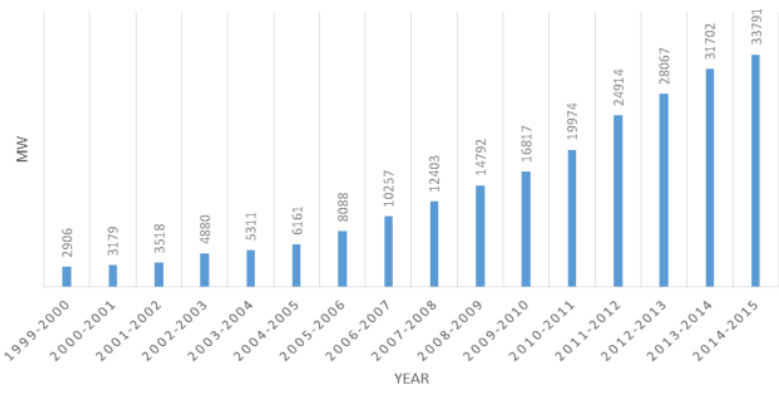

Figure 3.Renewable Energy Installed Capacity - Growth [3]

This work deals with the design and feasibility of a solar power plant in a academic E-blockof Thapar university to promote and aware about the advantages of use of solar energy in order to help India achieve its ambitious target of $100 \mathrm{GW}$ solar power and boost the renewable energy growth trend as shown in the figure 3.

\section{Description of study area of academic of E-Block}

Thapar University, one of the best technical university in the region is located in Patiala, Punjab and is a lush green campus of about 250 acre as shown in the figure 4 . It has several academic blocks and E-block is one of the block which is a building consisting of 2-floors and 16 lecture halls. The block is so located, that it's rooftop does have very minimal shadow areas but has good exposure to sun irradiance during the operating hours i.e. lecture hours.

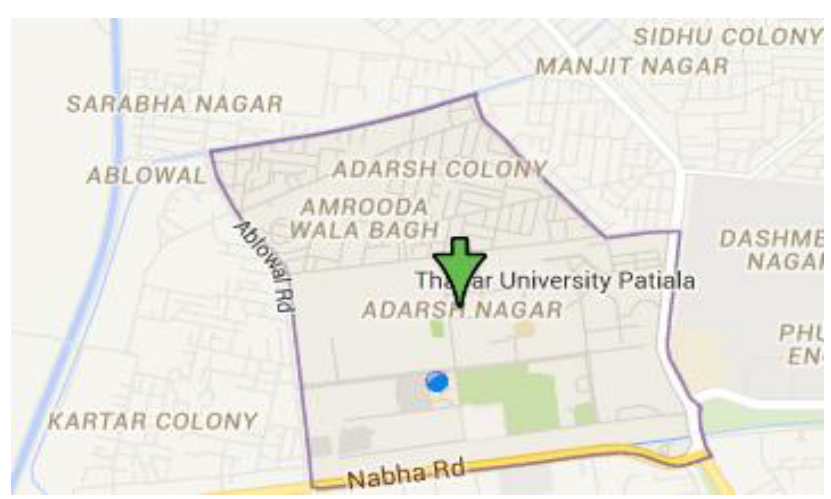

Figure4.Location OfThapar University On Map

The co-ordinates of the block are-

Latitude - $30^{\circ} 21^{\prime} 12.62^{\prime \prime} \mathrm{N}$ and Longitude $76^{\circ} 22^{\prime} 20.15^{\prime \prime}$ EThe top view of the block is shown in the figure 5.The block is a academic block with maximum load as lighting load or fan load.

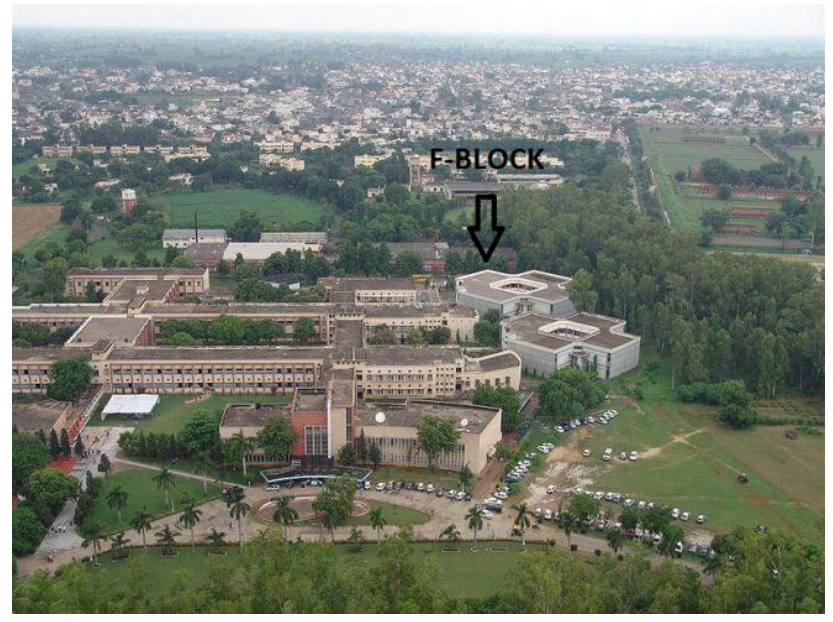

Figure 5.Top View Of E-Block

\section{Technical feasibility of the project}

The following section discusses the technical feasibility of the project. The technical feasibility includes the following factors-

i)Irradiation Analysis

ii)Connected Load Analysis

iii)Rooftop Analysis

iv)Shadow Analysis

v)Load Analysis

vi)Design of on-grid system

vii)Design of off-grid system

\subsection{Irradiation Analysis}

The figure 6 gives the solar irradiation at the location throughout the year. The average irradiance comes out to be $5.28 \mathrm{KWh} / \mathrm{m}^{2} /$ day. The average solar power plant takes $9.3 \mathrm{~m}^{2}$ for $1 \mathrm{KW}$ and plant runs for about 6 hours. Thus producing 6 units (KWh) in a day. Therefore, For $9.3 \mathrm{~m}^{2}$ it produces 6 units in a day $\&$

For $1 \mathrm{~m}^{2}$ it will produce 6/9.3 units in a day. 


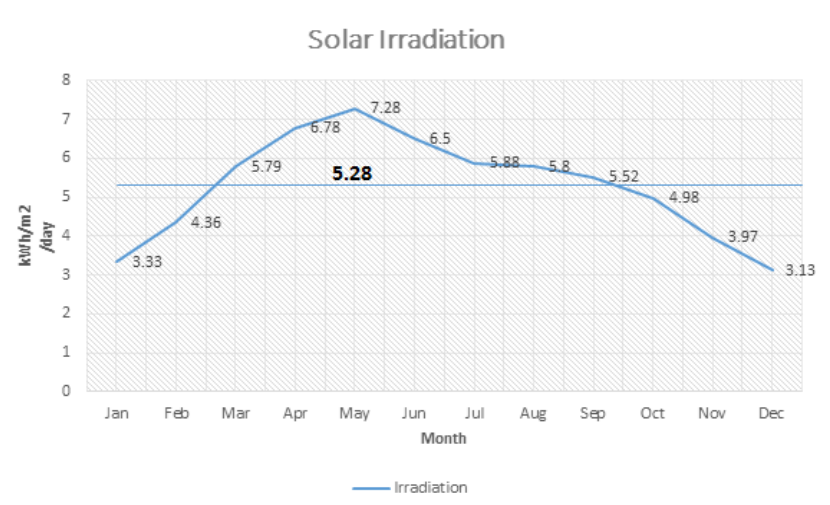

Figure 6. Irradiation Analysis Of Patiala[4]

Therefore, the plant will make $0.645 \mathrm{KWh} / \mathrm{m}^{2} /$ day which is way below the solar irradiance in every month. Hence,
Hence, if everything will be running, it will withdraw $54.6 \mathrm{KW}$ power. Through, this we also got to know about the number of watt-hours of the block. This is needed for the calculations of the off-grid system.

\subsection{Rooftop Analysis}

The rooftop analysis of the block is done to check the available rooftop area and the shadow area and to find the south-facing direction as the south facing installation of panels gives optimized result in- Building height $=10 \mathrm{~m}$

$\&$ Parafitt wall height $=1 \mathrm{~m} \& \mathrm{Width}=250 \mathrm{~m}$. Also, it is suggested to place panels at an angle of $30^{\circ}$ for best results and to capture maximum power. The CAD drawing of the block is given in the figure 8 .

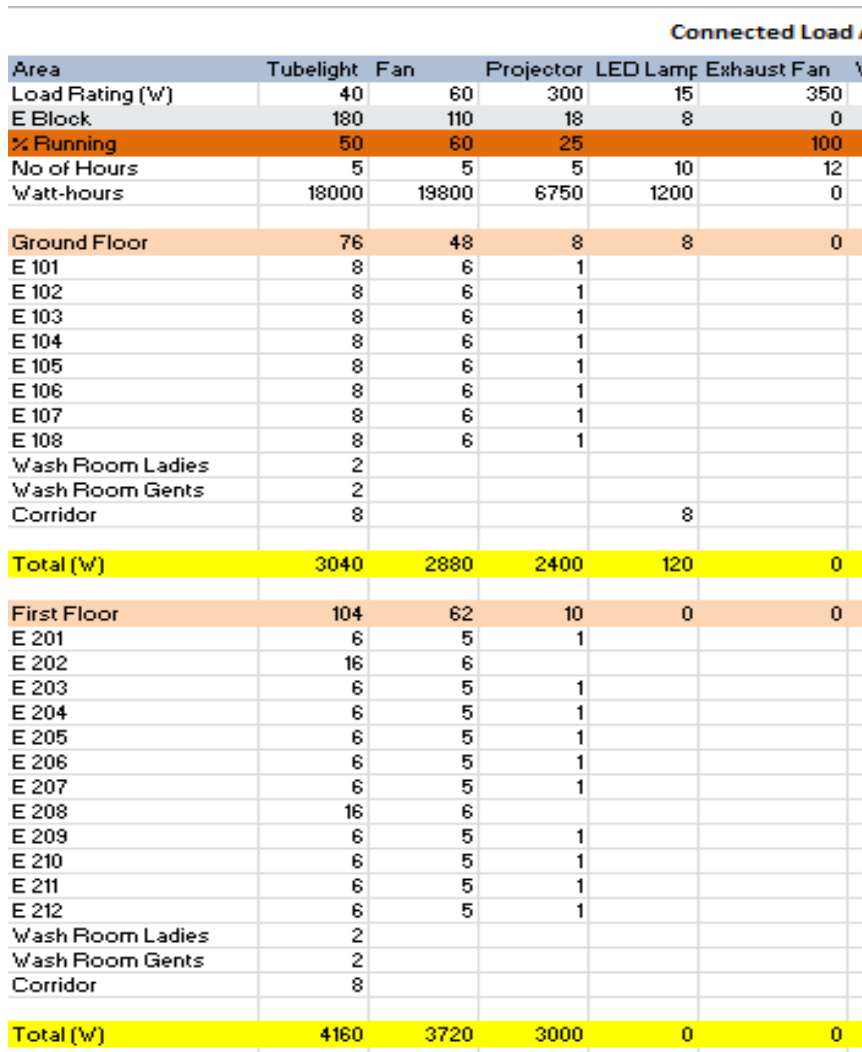

Figure .7 Connected Load Analysis Of E-Block

plant will get the adequate irradiance for maximum performance throughout the year. Yet, there is difference in performance of the plant throughout the year due to the difference in temperature which affects the performance of the plant.

\subsection{Connected Load Analysis}

The figure 7 shows the connected load analysis of the block. In this, we counted each and every load of the block. The total connected load of the block came out to be $=54.6 \mathrm{KW}$

For the first floor it came out to be $=\mathbf{3 0 . 9 2} \mathbf{K W}$

For the ground floor it came out to be $=23.68 \mathrm{KW}$

\begin{tabular}{|c|c|c|c|c|c|c|}
\hline an & Water Cooler & Repeater & CCTV & $5 \mathrm{Amp} S w$ & 16 Amp Switch & \multirow{2}{*}{ Total [ $\mathrm{W}$ '] } \\
\hline 350 & 1200 & 10 & POE & 100 & 1000 & \\
\hline 0 & 2 & 8 & 2 & 108 & 22 & \\
\hline 100 & & & & & & \\
\hline 12 & 15 & 15 & 24 & 0 & 0 & Wh \\
\hline 0 & 36000 & 1200 & 0 & 0 & 0 & 82950 \\
\hline
\end{tabular}

$\begin{array}{lll}0 & 1 & 4\end{array}$

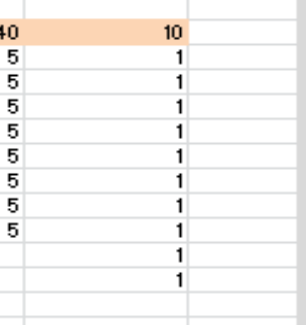

$0 \quad 1200$
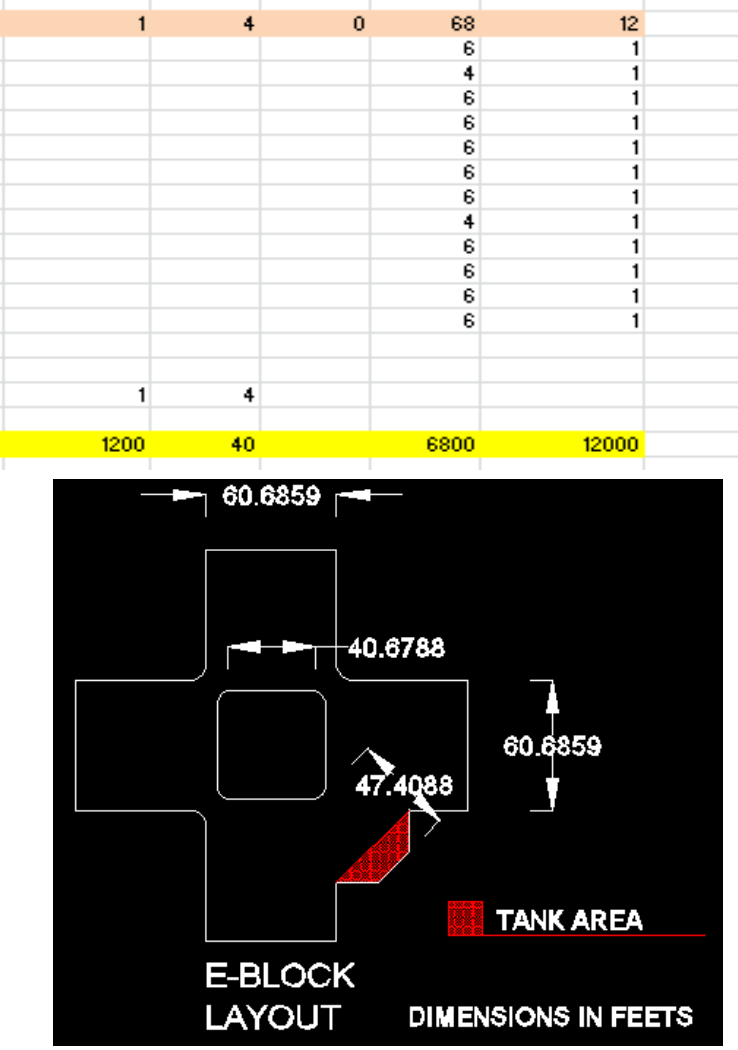

30920

Figure 8. CAD Drawing Of E-Block 


\subsection{Shadow Analysis}

It was observed that some of the area has shadow of nearby tress, parafitt and tank during the operating hours. This usable area is estimated about $52000 \mathrm{ft}^{\wedge} 2$. As $1 \mathrm{KW}$ plant requires about $100 \mathrm{ft}^{\wedge} 2$ area. Thus, $50 \mathrm{KW}$ can be proposed on the rooftop i.e. its maximum capacity.

\subsection{Load Analysis}

The load analysis of the block is very essential which is carried out bybar graph based on the university's electricity bills as shown in the figure 9. From load analysis we conclude that peak consumption is in September of $2846 \mathrm{KWh}$ and minimum consumption is in February of $1176 \mathrm{KWh}$ and also we calculated average consumption from this.

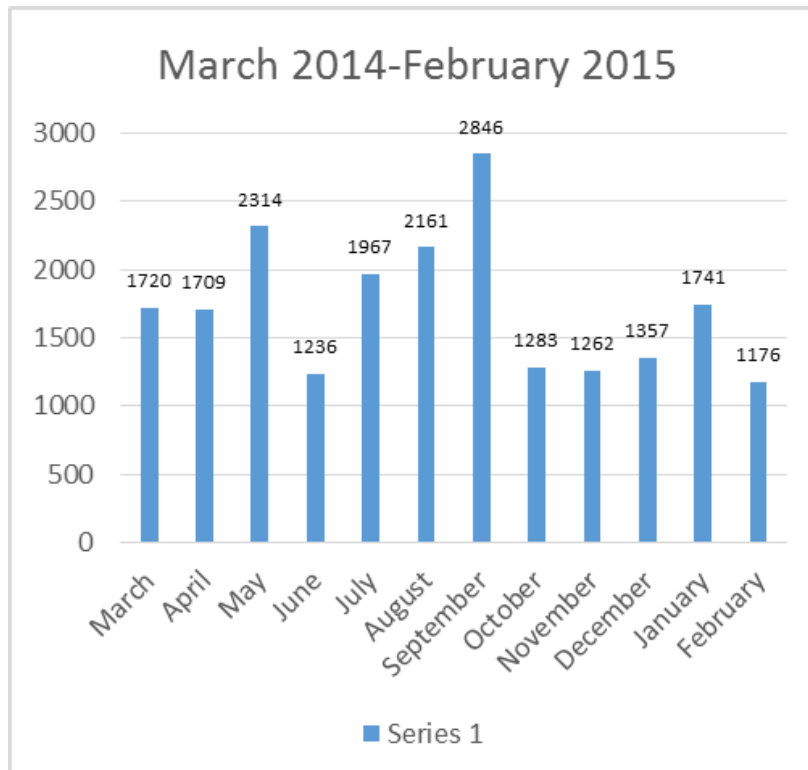

Figure 9. Load Analysis Of E-Block

\subsection{Design of on-grid system}

Calculations for the design-

Average monthly consumption of the block = $((1720+1709+2314+1236+1967+2161+2846+1283+1262$ $+1357+1741+1176) / 12)=1731 \mathrm{KWh} \&$ If we assume 320 sunny days in a year, then in a month there will be about $320 / 12=26$ sunny days. We are assuming that a plant works for 6 hours in a day. Number of operational hours in a month $=156$ hours. Plant needed for average monthly consumption $=1731 / 156 \approx 12 \mathrm{KW} \&$ Plant needed for peak consumption $=2846 / 156 \approx$ $19 \mathrm{KW} \&$ Plant needed for minimum consumption $=$ $1176 / 156 \approx 8 \mathrm{KW} \&$ Maximum capacity of the block $=50$ $\mathrm{KW}$. The summary of the points of design are given in figure 10 .

\section{Concluding Remarks For Design-}

If the consumer is interested in exporting the energy to grid, then it should go for the maximum capacity block can accommodate. Here, it is $50 \mathrm{KW}$. If, a consumer doesn't want to export then, it should go with the average consumption which is $12 \mathrm{KW}$. The plant should be installed in 3 arrays of $4 \mathrm{KW}$ each, so that when consumption is $8 \mathrm{KW}$, one of the array should be turned off. Here, in our design we will be assuming it to be of 50 $\mathrm{KW}$ as the university wants to export the energy to other blocks.

\begin{tabular}{|l|l|}
\hline \multicolumn{1}{|c|}{ DATA OF E-BLOCK } \\
\hline Average yearly consumption of block & $20772 \mathrm{KWh}$ \\
\hline Average monthly consumption of the block & $1731 \mathrm{KWh}$ \\
\hline Peak load of the block for a month & $2846 \mathrm{KWh}$ (Sept.) \\
\hline Minimum load of the block for a month & $1176 \mathrm{KWh}$ (February) \\
\hline Plant needed for average monthly consumption & $12 \mathrm{KW}$ \\
\hline Plant needed for peak consumption & $19 \mathrm{KW}$ \\
\hline Plant needed for minimum consumption & $8 \mathrm{KW}$ \\
\hline Area needed per KW & $100 \mathrm{ft}^{\wedge} 2$ \\
\hline Approx. Rooftop area of block per roof & $50000 \mathrm{ft} \wedge 2$ \\
\hline Maximum capacity of the block & $50 \mathrm{KW}$ \\
\hline
\end{tabular}

Figure 10. Summary Of Points Of Design

Design for $50 \mathrm{KWp}$ system-

Panel rating $=250 \mathrm{~W}, 24 \mathrm{~V} \&$ Rating of grid-tie inverter $=$ $50 \mathrm{KW}$. The general voltage rating of grid tie-inverter of $50 \mathrm{KW}$ is $360 \mathrm{~V}$. Hence array of 15, 250W panels will be in series.The CAD of installation is shown in the figure 11.The block diagram of installation is shoen in figure 12.

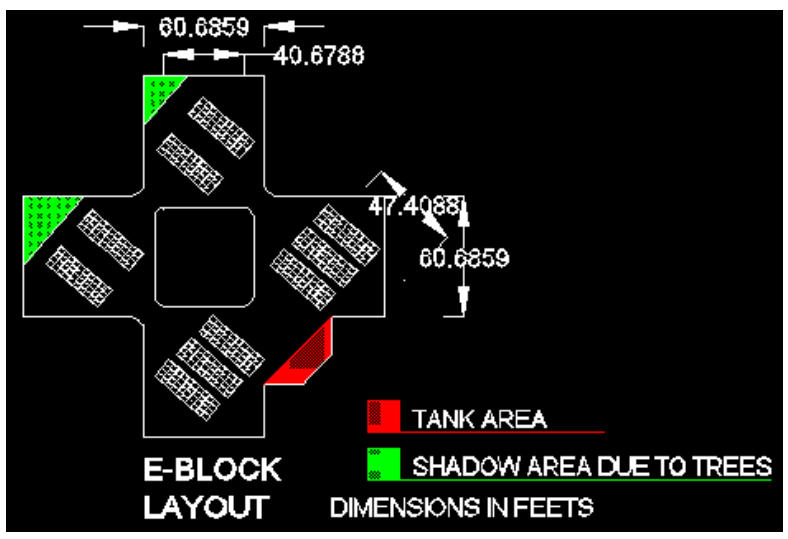

Figure 11.CAD Of The $50 \mathrm{KWp}$ Installation

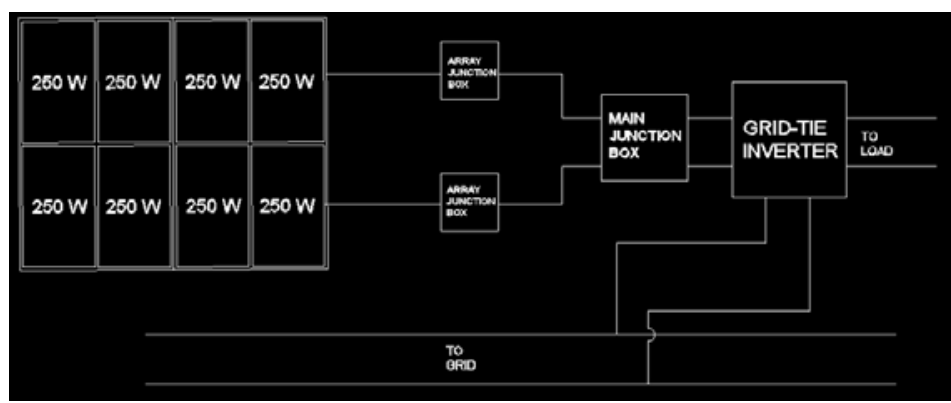

Figure 12. Block Diagram Of On-Grid Installation 


\subsection{Design of off-grid system}

For the, off-grid system, the design calculations are-

Number of watt-hours $=82,950 \mathrm{KWh}$. Assuming, to use $12 \mathrm{~V}$ batteries and multiplying 1.25 to accommodatedeepdischargeeffect in the batteries, the $\mathrm{Ah}$ rating of the batteryis $=82950 / 12 * 1.25=8641 \mathrm{Ah} \approx$

$9000 \mathrm{Ah}$. The battery bank should be designed in such a way to give9000 Ah rating. Using the thumb rule that, Plant rating $=2 *$ battery rating $=2 * 9000=18000 \mathrm{~W} \approx \mathbf{1 8}$ KW. Hence, $18 \mathrm{KW}$ willbe the apt size for the off-grid system.Voltage rating of charge controller = 12V\&Current rating of charge controller $=18000 / 12=$ $1500 \mathrm{~A}$

The arrays should be made of the panels, subject to availability and rating of the charge controller and rating of the inverter. The block diagram of installation is shown in figure 13.

Induction loadingeffect for the design of inverter Due, to high power drawn by the induction motorloads during starting or transients, the inverter is designed to handle these.For this, we again add the watt-hours by the induction motorloads. Thus, new watt-hours = $82950+19800+36000=138750 \approx 15 \mathrm{KW}$ which is less than $18 \mathrm{KW}$.

Rating of inverter $=\mathbf{1 8 K W}$

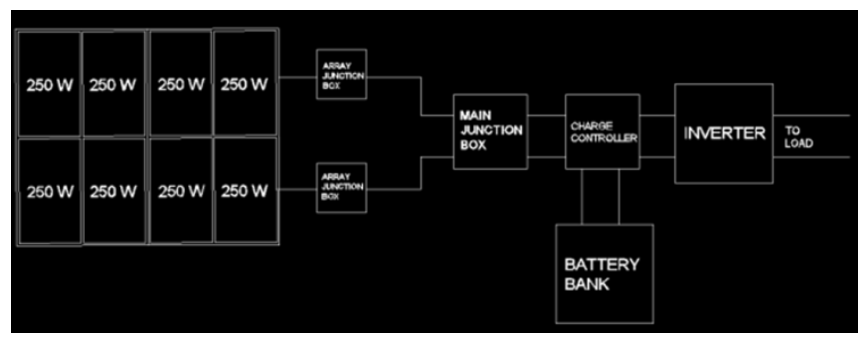

Figure 13. Block Diagram of Off-Grid Installation

\section{Finanacial feasibility of the project}

Most important is the financial feasibility of project. Here, also all the factors which could affect financial feasibility are considered as follows-

1) Cost analysis

2) Payback period

3) Funding options

4) Carbon points and carbon trading analysis

\subsection{Cost Analysis}

The cost analysis for $50 \mathrm{KW}$ on-grid project has Approx. expenditure of the installation and maintainence asRs. 50 Lakh. Approx. units produced in a day will be $=50 * 6$ $=300 \mathrm{Kwh}$ (Assuming 6 hours operation of the plant)\&Yearly units (assuming 320 sunny days) = $300 * 320=96,000$ units \&Yearly savings (assuming Rs. $7.5 /$ unit rate $)=7,20,000$.

\subsection{Payback period}

The investment has to be justified by its payback period which tells us savings on the part of the university. The payback comes out to be $=5000000 / 720000=6.94$ years (without accelerated depreciation)\&Profit in 25 years $=$ $(25-7) * 720000=1,29,60,000$. The figure 14 tells us the trend of payback vs size of the plant. The figure 15 shows us the profit in 25 years vs size of the plant.

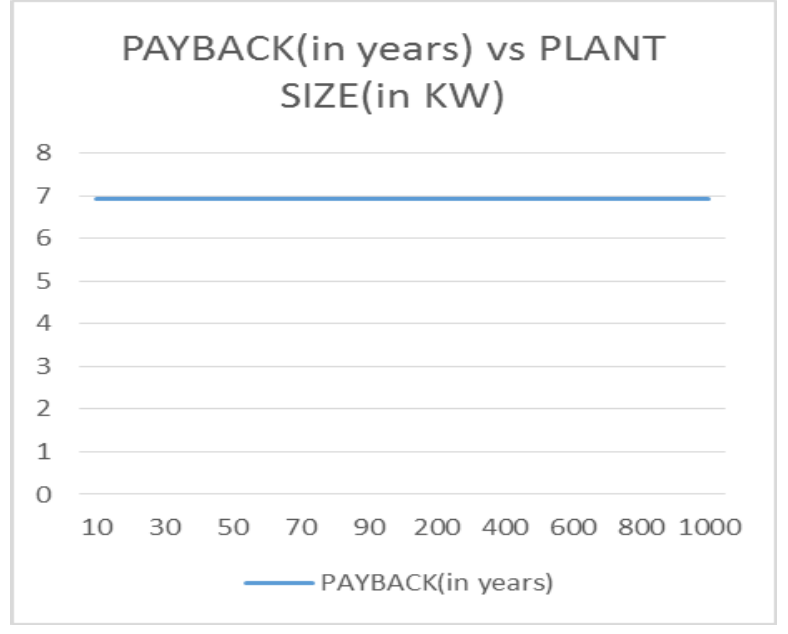

Figure 14. Payback (In Years) Vs Plant Size (In KW)

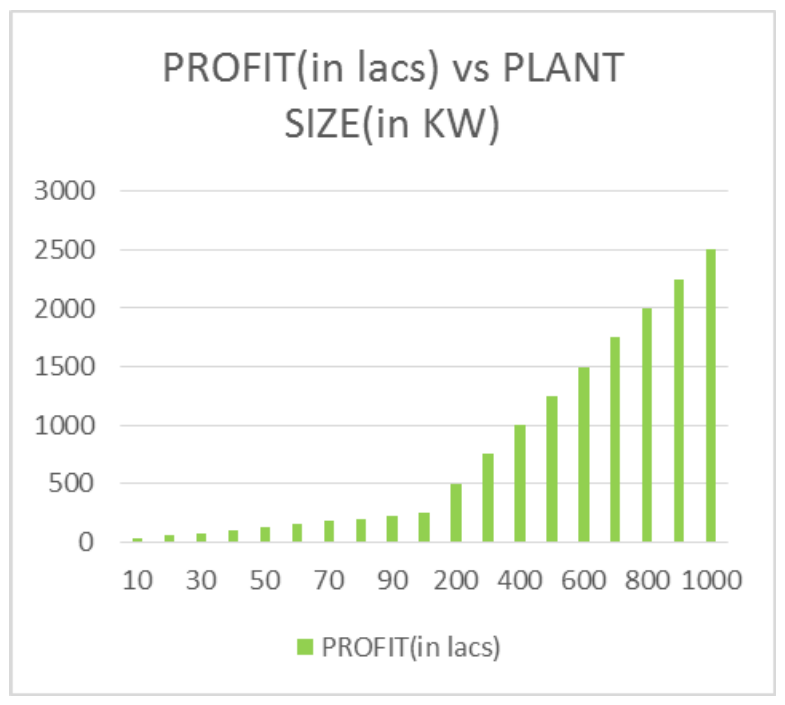

Figure 15. Profit In 25 Years (In Lacs) Vs Plant Size (In KW)

\subsection{Funding Options}

The various funding options for this project are-

(i)EPC (Engineering, Procurement and Construction)

(ii)PPA (Power Purchase Agreement)

(iii)CSR (Corporate Social Responsibility)

(iv)Organizations like MNRE, World bank, etc.

\section{Conclusion}

A 50KWp on-grid type solar power plant should be installed in the rooftop of academic E-block which will produce approximately 300 units in a day resulting in the optimal use of resources available in the form of solar 
energy for the grid and load during the operating hours. In our case university, wants to export the energy to the grid so on-grid system will be more beneficial than the off-grid system. This will also result in the payback of investment in 7 years and will yield university an approx. profit of Rs. 1.3 Crore in next 25 years.

\section{References}

1. http://mnre.gov.in/file-manager/annual-report/20142015/EN/Chapter\%201/chapter 1. htm

2. http://mnre.gov.in/file-manager/annual-report/20142015/EN/Chapter\%201/chapter 1.htm

3. http://mnre.gov.in/file-manager/annual-report/20142015/EN/Chapter\%201/chapter 1.htm

4. Souvik Ganguli, Jasvir Singh, Etspg, International Journal Of Applied Engineering Resea rch, Dindigul, Volume 1, No.2, 255 (2010)

5. H. Hippert, C. Pedreira, and R. Souza, "Neural networks for short-term load forecasting: A review and evaluation," IEEE Trans. Power Syst., vol. 16, no. 1 , pp. $44-55,(2001)$

6. S. J. Huang and K. R. Shih, "Short-term load forecasting via ARMA model identification including non Gaussian process considerations," IEEE Trans. Power Syst, vol. 18, no. 2, pp. 673-679, (2003)

7. J. W. Taylor, "Short-term load electricity demand forecasting using double seasonal exponential smoothing," Journal of the Operational Research Society, vol. 54, pp. 799-805, (2003)

8. M. S. Kandil, S. M. El-Debeiky, and N. E. Hasanien, "Long-term load forecasting for fast developing utility using a knowledge-based expert system," IEEE Trans. Power System, vol. 17, no. 2, pp. 491 496 (2002)

9. K. B. Song, Y. S. Baek, D. H. Hong, and G. Jang, "Short-term load forecasting for the holidays using fuzzy linear regression method," IEEE Trans. Power System, vol. 20, no. 1, pp. 96-101, (2005)

10. S.Fan and L. Chen, "Short-term load forecasting based on an adaptive hybrid method," IEEE Trans. Power System, vol. 21, no. 1, pp. 392-401, (2006) 